\title{
Patient Pathways for Comprehensive Care Networks - A Development Method and Lessons from its Application in Oncology Care
}

\author{
Peggy Richter \\ TU Dresden, Germany \\ peggy.richter2@tu-dresden.de
}

\author{
Hannes Schlieter \\ TU Dresden, Germany \\ hannes.schlieter@tu-dresden.de
}

\begin{abstract}
Patient pathways are recognized as a valuable tool to support standardization, comparability, quality, and transparency of care processes in comprehensive care networks. Still, existing development approaches lack real practical guidance as well as an integration of the network and patient perspectives. Therefore, a usercentered and requirements-based approach was chosen to design a patient pathway development method. It defines a role model and procedural steps. The method's innovative character lies in the development of generic patient pathway templates to be adapted to national, regional, and local conditions of specific comprehensive care networks. The method was positively assessed in terms of demonstrating its applicability and the fulfilment of user requirements with a use case from oncology care - the development of a colorectal cancer patient pathway template. This work drives the standardization of patient pathway development and their large-scale implementation in comprehensive care networks, supporting the analysis, design, and optimization of healthcare processes.
\end{abstract}

\section{Introduction}

Patient pathways are used to plan and manage the whole process of care for a specific patient type, especially for patients with complex, long-term conditions, by defining goals and milestones while also supporting mutual decision-making by the patient and her/his multidisciplinary care team collaborating in a comprehensive network of care providers [1]-[3]. Against the background of an increasing demand for integrated care delivery in a coordinated network of health service providers [4], [5], the concept of patient pathways becomes even more important. For example, in cancer care - with cancer being one of the most common and costly diseases in western countries [6] patient pathways are regarded as important tools to improve patient information, to implement evidence- based medical guideline recommendations as well as to support seamless, optimal care in a comprehensive network of different health service providers [7]. However, uniform and standardized practical support for the development of patient pathways is not given yet. There are different procedural frameworks for the development and implementation of pathways (e.g. [8][13]), but they are rather generic and not described in such detail as to provide practical guidance and support for the users. Also, pathway development is mostly addressed for single health care institutions, not the entire care network involved in the care process of patients. Also, the clinical rather than the patient perspective is the focus so far (e.g. [1], [14]).

To centrally support network governance, e.g. by national or international non-profit organizations, and to increase the quality of care across care networks, a template-based patient pathway development approach is called for [9]. Patient pathway templates for particular patient types can function as guiding blueprints for the development of network-specific ones by adapting them to national, regional, and local specifics (e.g. availability of technologies or national guidelines on follow-up timeframes). This approach would allow for better comparability, consistency, and increased uniformity of care provision across different comprehensive care networks [9]. Also, similar to the general advantages of reference models [15], an increase of safety for patients and health service providers, the reduction of risks and costs during pathway development (e.g. by shortening the development time), and an increase of pathway quality can be expected. Still, the potentials of reusable patient pathway templates are not exploited yet.

Addressing these gaps and elaborating on the template-based patient pathway approach, this paper aims to provide practical guidance with a method for the development of patient pathways in comprehensive care networks. The focus is on the construction and design of patient pathway templates and on highlighting the network and patient view. Therefore, a user-centered and use-case-driven approach is chosen. 
The remainder of the paper is structured as follows. In section 2, the used methods are described. The requirements analysis for practical guidance of patient pathway development is conducted in section 3 . Based on this and to practically guide the development of patient pathways, a procedural model and a role model for a patient pathway development method, hereafter abbreviated with $\mathrm{Pa}^{2} \mathrm{D}$-method, are described in section 4. In section 5, the method is assessed in terms of demonstrating its applicability and demonstrating the fulfillment of user requirements with an example use case in oncology care. The paper closes with a discussion and a conclusion in sections 6 and 7 .

\section{Method}

For the design and testing of a patient pathway development method for comprehensive care networks, the design science paradigm was followed [16]. With the aim to provide a user-centered and practical method, we used a qualitative data collection approach by defining user requirements based on user stories. A user story is a statement written from the end user's perspective [17]. It represents a short, informal description of a requirement in the format "As a $<$ role $>$ I want $<$ something $>$ so that $<$ benefit $>$." We set up a workshop and asked 25 people to describe user stories from their own or a chosen perspective, i.e. role. The workshop included international participants who are part of an international project consortium in the domain of cancer care. The group consisted of health care providers (e. g., oncologists, nurses), managers of health care organizations, methodologists (e. g., medical guideline developers), representatives of national authorities and international and national health organizations, patient representatives as well as researchers. The participants were given the example user story "As a physician in a patient pathway development board I want to use an agreed upon pathway representation format so that all colleagues in [comprehensive cancer care networks] can exchange pathways across networks". Altogether, 33 user stories ${ }^{1}$ were collected. They were analyzed using a qualitative content analysis according to Mayring [18] with a coding scheme derived from a previous systematic literature review of existing pathway methods conducted by the authors [9]. Therewith, we derived requirements for the intended patient pathway development method. We focused on construction- and design-related requirements which specify the development phase for patient pathways. The roles specified in the user stories together with the derived requirements were used to develop the $\mathrm{Pa}^{2} \mathrm{D}$-method. We demonstrate its applicability with the development of a colorectal cancer patient pathway template for comprehensive cancer care networks. The experiences during the application were used to assess the method and to derive lessons for improvement. The development team of the colorectal cancer template was asked to answer an online questionnaire. It addressed the degree of fulfilling the defined requirements with the $\mathrm{Pa}^{2} \mathrm{D}$-method as well as for the personal (positive and negative) perception of the application of the method.

\section{Requirements analysis}

The analysis of the user stories resulted in the identification of functional and non-functional requirements which cover both general procedural issues as well as the representation of patient pathways. Functional requirements describe the desired functions of the intended patient pathway development method. We identified seven functional requirements R1 to R7. They are described in the following. An exemplary user story for each requirement is given in Table 1 .

R1-Patient pathways for comprehensive care networks should have uniform template character and provide adaptation notes for their implementation to particular care networks. The development method should produce generic patient pathway templates, i.e. standard pathway patterns, which are not specific for a particular care network but provide a framing of essential building blocks for each phase of care for a specific disease. The templates function as guidance for the development of network-specific patient pathways and provide adaptation notes for implementation, e.g. required/optional parts or adaptation instructions considering national, regional, or local conditions.

$R 2$ - Patient pathways should be disease-specific. They should be designed for a specific patient type, e.g. patients with a specific tumor entity, and thus describe in- and exclusion criteria for entering the pathway.

R3 - Patient pathways should be developed by a multi-stakeholder working group. This means, they should be developed by a working group consisting of people representing the roles and organizations involved in care provision along the whole pathway. This should also include the patient perspective.

R4 - A patient pathway development method should define the group processes. This includes for example the definition of group composition, roles, consensus finding, decision-, prioritization- and review processes.

R5 - Patient pathways should be developed based on scientific evidence, especially medical guideline

\footnotetext{
1 The full list of user stories can be provided by the authors.
} 
recommendations. The link of the patient pathway content to its evidence base should be maintained. Therefore, patient pathways should provide concepts to describe the evidence level of a recommendation (e.g. pathway step/decision) and to link the evidence source.

R6 - A patient pathway should sequence obligatory and optional steps and the relevant information along all phases of care in a comprehensive care network for the involved care providers and the patient. Relevant information are tasks, decisions, roles, process flows, time restrictions, information objects, quality aspects.

$R 7$ - Patient pathways should provide a patient view to support shared decision-making and individualization. They should represent steps the patient is directly involved in (e.g. consultation, consent) or has to perform him-/herself. They should allow for individualization to patient-specific situations, e.g. patient preferences or comorbidities.

\section{Table 1. Functional requirements}

\begin{tabular}{|c|c|}
\hline No. & Example user story \\
\hline R1 & $\begin{array}{l}\text { "As a manager I want the methodology to } \\
\text { provide guidelines on the pathway development } \\
\text { and identify the essential building blocks of a } \\
\text { pathway so that pathways can be developed and } \\
\text { adopted to the local healthcare context of the } \\
\text { [comprehensive care network]." }\end{array}$ \\
\hline $\mathbf{R 2}$ & $\begin{array}{l}\text { "As a medical doctor in training I want patient } \\
\text { pathways to be tumor-specific so that I can } \\
\text { provide quality of care." }\end{array}$ \\
\hline $\mathbf{R 3}$ & $\begin{array}{l}\text { "As a patient I want patient views and } \\
\text { perspectives to be integrated in the [pathway } \\
\text { development] process in order to integrate } \\
\text { shared (informed) decision-making in patient } \\
\text { pathway development." }\end{array}$ \\
\hline $\mathbf{R 4}$ & $\begin{array}{l}\text { "As a methodologist in a [patient pathway } \\
\text { development] board I want to have } \\
\text { information/agreement on consensus finding } \\
\text { process so that bias in [patient pathway } \\
\text { development] is controlled." }\end{array}$ \\
\hline R5 & $\begin{array}{l}\text { "As a methodologist in a [patient pathway } \\
\text { development] board I want to have a description } \\
\text { of the evidence base and the strength of } \\
\text { certainty in order to get transparent and } \\
\text { reproducible results." }\end{array}$ \\
\hline R6 & $\begin{array}{l}\text { "As national authority I want to have a mean to } \\
\text { define obligatory tasks within the pathway." }\end{array}$ \\
\hline R7 & $\begin{array}{l}\text { "As a patient I want a patient pathway that I can } \\
\text { understand and that helps me make decisions } \\
\text { together with my doctor and my family so that I } \\
\text { can be in control of what is happening and to } \\
\text { check if everything is going according to my }\end{array}$ \\
\hline
\end{tabular}

Additionally, non-functional requirements were identified. These specify criteria that can be used to evaluate the method's performance in terms of quality criteria. A method to develop patient pathways for comprehensive care networks should be generic, easyto-manage (workable), inclusive, and easy-tounderstand (e.g. "As a [...] network advisor I want an inspiring, workable, generic method for designing and implementing patient pathways [...]"). A standardized, clear and easy-to-analyze representation format of patient pathways should be used (e.g. "As a (healthcare) researcher I want conceptually clear and 'easy to analyze' $[\ldots]$ representation so that it facilitates efficient, transparent and reproducible research").

\section{Patient pathway development method}

According to Brinkkemper (1996), "[a] method is an approach to perform a systems development project, based on a specific way of thinking, consisting of directions and rules, structured in a systematic way in development activities with corresponding development products" [19]. Patient pathways are a processual view of a comprehensive care network which is a sociotechnical system [20]. To systematically guide and support their development, the $\mathrm{Pa}^{2} \mathrm{D}$-method is proposed. In the following, its role model and the procedural model are described.

\subsection{Roles}

To specify the tasks and expected qualifications of people applying the $\mathrm{Pa}^{2} \mathrm{D}$-method, the involved roles are summarized in Table 2.

To meet the requirement of template-based pathway development (see R1, sec. 3), the roles patient pathway template designer and patient pathway designer are distinguished. The former develops the template and prepares it for reuse whereas the latter adapts the patient pathway template to national, regional, or local specifics of a comprehensive care network. Both roles should be modelling experts and experienced in the application of process (pathway) modelling languages. The patient pathway template designer additionally needs to be familiar with reference modelling techniques, especially pathway templates. Depending on the organizational context, both roles can be assigned to one person.

For the development of a patient pathway template, the knowledge input from domain experts of the specific health care phenomenon, e.g. a health condition or disease for which the patient pathway (template) shall be developed, is necessary. The content of the patient pathway template, e.g. activities, process-, information- 
Table 2. Role model of the Pa2D-method ${ }^{2}$

\begin{tabular}{|c|c|}
\hline Task & Qualification \\
\hline \multicolumn{2}{|c|}{ Patient pathway template designer } \\
\hline $\begin{array}{l}\text { Ensures adequate use of the } \\
\text { modelling language; excerpts the } \\
\text { knowledge of the domain } \\
\text { experts and transfers it into the } \\
\text { PP template; prepares PP } \\
\text { templates for reuse }\end{array}$ & $\begin{array}{l}\text { Modelling expert: } \\
\text { computer } \\
\text { scientist, } \\
\text { information } \\
\text { systems engineer }\end{array}$ \\
\hline \multicolumn{2}{|l|}{ Patient pathway designer } \\
\hline $\begin{array}{l}\text { Ensures the correct application } \\
\text { of the PP template; adapts the PP } \\
\text { template model to CCN } \\
\text { specifics; models the PP } \\
\text { elements }\end{array}$ & $\begin{array}{l}\text { Modelling expert: } \\
\text { computer } \\
\text { scientist, } \\
\text { information } \\
\text { systems engineer }\end{array}$ \\
\hline \multicolumn{2}{|c|}{ Patient pathway template stakeholder } \\
\hline $\begin{array}{l}\text { Gives domain input for PP } \\
\text { template development; reviews } \\
\text { and approves PP template } \\
\text { contents and representation }\end{array}$ & $\begin{array}{l}\text { Domain expert: } \\
\text { representative of } \\
\text { interest group }\end{array}$ \\
\hline \multicolumn{2}{|l|}{ Patient pathway user } \\
\hline $\begin{array}{l}\text { Uses the developed, approved } \\
\text { PP and implements it in the } \\
\text { accounted CCN unit; supports } \\
\text { with the adaptation of the PP } \\
\text { template, e.g. to CCN specifics; } \\
\text { participates in approving the PP } \\
\text { for the CCN }\end{array}$ & $\begin{array}{l}\text { Domain expert: } \\
\text { representatives of } \\
\text { involved } \mathrm{CCN} \\
\text { units along the PP }\end{array}$ \\
\hline \multicolumn{2}{|l|}{ Method expert } \\
\hline $\begin{array}{l}\text { Is particularly familiar with } \\
\text { template-based pathway design; } \\
\text { leads the execution of the } \\
\text { method and conducts necessary } \\
\text { trainings on the method; } \\
\text { recognizes and implements } \\
\text { change requests to the method; } \\
\text { involves in the continuous } \\
\text { optimization of the method }\end{array}$ & $\begin{array}{l}\text { Method expert: } \\
\text { business } \\
\text { economist, } \\
\text { information } \\
\text { systems engineer }\end{array}$ \\
\hline
\end{tabular}

or resource flows, involved roles, obligatory and optional parts, should be provided by a team of representatives of different interest groups (see R3, sec. 3 ). These patient pathway template stakeholders should involve health policy representatives (e.g. national authorities, health policy developers, or advisors), representatives of national or international health care organizations or associations (e.g. representatives of accreditation organizations or medical guideline development), researchers, and representatives of involved units of comprehensive care networks (e.g. network managers, quality managers, healthcare professionals). To also explicitly include the patient perspective (see R7, sec. 3), representatives of patient organizations should be involved in the patient pathway template development.

Patient pathway templates are applied to specific comprehensive care networks. The adaptation of the template is supported by patient pathway users, who are familiar with the specific characteristics of the own comprehensive care network. Also, they implement the approved patient pathway. The patient pathway users primarily are medical, nursing, and supportive care professionals. Also, administrative staff and the patient him-/herself are relevant representatives. Thus, patient pathway users are a subgroup of patient pathway template stakeholders and people could be assigned both roles at the same time.

The quality and progress of the patient pathway development process should be assured and monitored by a method expert. This role also includes the responsibility for the training and guidance of the project team members in terms of the $\mathrm{Pa}^{2} \mathrm{D}$-method.

\subsection{Procedural model}

A typical project flow for the development and implementation of template-based patient pathways in comprehensive care networks consists of the main phases as shown in Figure 1. The process consists of two major parts, which are first, the development of a generic patient pathway template for a specific disease (see upper part of Figure 1) and second, the templatebased development of patient pathways for a particular comprehensive care network by adapting the template to national, regional, and local context (see lower part of Figure 1). This distinction is in particular due to requirement R1 (see sec. 3).

The project institution for template development comprises the establishment of the multidisciplinary patient pathway template development team (working group) [8], [10], [13], [21]. In detail, this team shall consist of patient pathway template designer(s), patient pathway template stakeholders including patient pathway users, and method expert(s) as described in the $\mathrm{Pa}^{2} \mathrm{D}$-method's role model in section 4.1. Also, the team shall be trained and educated about the development process [8], [13] and the consensus finding process shall be defined [9] (see R3 and R4, sec. 3). The project plan, e.g. timetables, tasks, responsibilities, and resources, should be set up [10], [13]. The definition of the addressed patient population is necessary.

\footnotetext{
2 "Patient pathway" is abbreviated with PP and "comprehensive care network" with CCN in Tables and Figures of this article.
} 


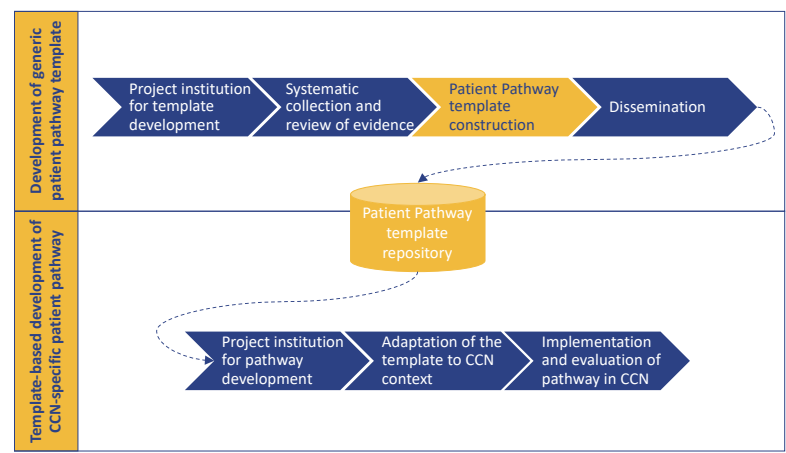

\section{Figure 1. Main phases of the $\mathrm{Pa}^{2} \mathrm{D}$-method for the development of generic templates and their adaptation in CCNs}

The systematic collection and review of evidence should use literature reviews to analyze and assess the current state of existing evidence for the whole continuum of care covered by the patient pathway [8], [10], [11], [21] (see R2 and R3, sec. 3). This step should also include a review of existing patient pathways for the addressed patient type in the scientific and grey literature, e.g. published by healthcare organizations. In this context, similar concepts such as care pathway, clinical pathway, or patient journey should be included in the search as well since they are often used synonymously [2], [9]. The collection of evidence should be carried out by the patient pathway template stakeholders and methodologically supported by the method expert. The collected literature and existing pathways are input for the following template construction phase.

The patient pathway template construction is the core phase of the $\mathrm{Pa}^{2} \mathrm{D}$-method and for this reason highlighted in yellow in Figure 1. In Table 3, the essential information of this phase is represented.

Table 3. External view on the phase "patient pathway template construction"

\begin{tabular}{|l|l|}
\hline Attribute & Description \\
\hline Objective & $\begin{array}{l}\text { Development of a reference PP template } \\
\text { in CCNs for specific patient population }\end{array}$ \\
\hline Input & $\begin{array}{l}\text { Current evidence (medical guidelines, } \\
\text { systematic reviews), existing pathways, } \\
\text { defined target patient population }\end{array}$ \\
\hline Output & Approved and agreed upon PP template \\
\hline $\begin{array}{l}\text { Roles } \\
\text { involved }\end{array}$ & $\begin{array}{l}\text { PP template designer(s), PP template } \\
\text { stakeholders, PP users, method experts }\end{array}$ \\
\hline Customers & CCNs applying the template \\
\hline
\end{tabular}

To practically guide the patient pathway template construction, a more detailed procedural description is provided. It consists of six steps, with the steps 2 to 5 being performed in an iterative manner (see Fig. 2). The scope definition (1) includes the specification of the phases along the continuum of care which are to be covered by the patient pathway template. Such phases are typically the network entry, prevention, diagnosis, treatment planning, treatment, follow-up, rehabilitation, supportive care, end-of-life care, and end of network care. The patient population as well as in- and exclusion criteria for patients entering the patient pathway need to be defined. Also, the modeling language and tool need to be selected [12]. The systematic literature review of standard languages and notations for the graphical modeling of patient care processes conducted by Mincarone et al. [22] showed, that the Business Process Model and Notation (BPMN) as well as the Unified Modeling Language (UML), especially its activity and use case diagrams, are well known and used approaches in health care practice. Domain-specific modeling language extensions such as BPMN4CP, a BPMN extension for care pathway modeling [23], could be used as well. Using this modeling language, the evidence level and evidence source can easily be represented and maintained within the pathway (template) model (see R5, sec. 3) by the patient pathway (template) designer.

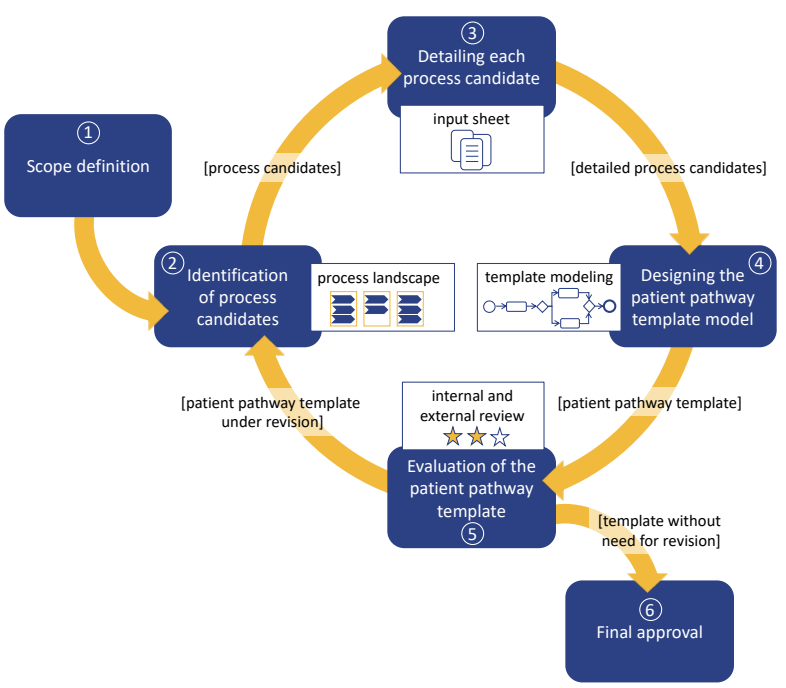

Figure 2. Inner view of the phase "patient pathway template construction"

The next step is the identification of process candidates (2), i.e. the identification of important patient pathway steps (process candidates) and linking them to the phases of care as defined in step (1). The result is called the process landscape. Therefore, the contents of existing pathways for the addressed patient population - identified with the previously conducted literature review - should be analyzed and mapped to structure the patient pathway landscape. If there are none available, this step can be solely performed in 
workshops with the domain experts and by including the recommendations from medical guidelines.

After the process landscape of the patient pathway template is defined, the detailing of each process candidate (3) follows. Therefore, a standardized input sheet is provided with the $\mathrm{Pa}^{2} \mathrm{D}$-method. It roots in the information collected for care pathway building as described with the 3-blackboard method by Vanhaecht et al. [24] but additionally includes perspectives to be covered in order to meet the patient pathway specific requirements from section 3 . The sheets should be filled in by the involved domain experts from the working group and with the results of analyzing the recommendations of medical guidelines and the articles identified with the conducted review on current evidence. To reduce the risk of distortion of included studies, the level of evidence must be paid attention to [25]. The input sheet is filled for each process candidate and requires the following information: (a) process name, (b) patient inclusion criteria (e.g. a subgroup of the generally addressed patient population), (c) responsible/ involved units of the comprehensive care network, (d) resources (e.g. medical technology, infrastructure), (e) process inputs (e.g. information, lab results), (f) detailed process description (i.e. interventions, decisions, consultations, tasks related to medical, nursing, and supportive care (i.e. psychological, physical, emotional, practical/ organizational, informational, spiritual, social support [26]), as well as to administration and activities the patient is responsible for), (g) times (i.e. time criticalities, time recommendations, iterations), (h) process outputs, (i) measures/ evaluation criteria (e.g. quality indicators to be assessed), (j) adaptation notes (i.e. required and optional steps; national, regional, local conditions to be considered for the implementation in a specific comprehensive care network).

Using the information from the filled input sheets, the next step is designing the patient pathway template model (4) by the patient pathway template designer. Therefore, the process landscape view is detailed by specifying the process candidates, their order and relations. This step can be supported by also including methods for the derivation of pathways from medical guideline recommendations (e.g. [27]). The template designer might identify information gaps, which need to be closed by getting feedback from the involved domain experts. This can happen either on short notice or during the following evaluation of the patient pathway template (5). With this step, feedback from the working group is collected and need for improvements of the template is identified. Furthermore, the template should also be reviewed by external domain experts, who were not involved in its development. As long as there is need for revision of the patient pathway template, the steps (2) to
(5) are performed in development cycles, detailing the template in each iteration. When the patient pathway template is evaluated with no need for further revisions, it gets final approval (6) from the working group.

After final approval, the patient pathway template for the specific disease should be disseminated and published, i.e. made available to the comprehensive care networks of interest. Therefore, a messaging and dissemination strategy needs to be developed and implemented [10], [11], [21]. With this regard, a common patient pathway template repository, provided and managed by a governing agency of the addressed comprehensive care networks or an international health care society, would be beneficial [9].

An approved patient pathway template can then be implemented in comprehensive care networks. When a network decides to develop a patient pathway based on such template, it first needs to establish a project institution for pathway development. This multidisciplinary project team should involve the patient pathway users of the network, patient pathway designer(s), and development method expert(s) as described in the $\mathrm{Pa}^{2} \mathrm{D}$-method's role model in section 4.1. The task of the working group is the adaptation of the template to the context of the comprehensive care network, i.e. to national, regional, and local specificities which are not part of the evidence base used for pathway template development (medical guidelines). Therefore, the adaptation notes specified with the template should be used. Reasons for adaptation could for example be national disease management programs or follow-up plans defining timeframes of a follow-up routine. The pathway also needs to be adapted in case of unavailable technologies or care professionals (e.g. the role of nurse specialists might differ between countries). After its development, the patient pathway needs to be piloted, implemented and continuously evaluated in the comprehensive care network (see [9] for a detailed list of steps necessary for this purpose, e.g. checking for new evidence).

\section{Demonstration and assessment}

For the evaluation of the $\mathrm{Pa}^{2} \mathrm{D}$-method, focusing on the template construction phase, we first, demonstrate its applicability using the example use case of integrated cancer care in section 5.1 and second, assess the $\mathrm{Pa}^{2} \mathrm{D}$ method in section 5.2 .

\subsection{Demonstration - the oncology use case}

The $\mathrm{Pa}^{2} \mathrm{D}$-method was tested by applying it in the context the large-scale European Joint Action iPAAC (Innovative Partnership for Action Against Cancer) 
aiming to develop innovative approaches to advances in cancer control. One focus is to improve the governance of integrated cancer care, e.g. by the development and implementation of patient pathways in comprehensive cancer care networks (CCCNs). "A CCCN consists of multiple units belonging to different institutions dedicated to research, prevention, diagnosis, treatment, follow-up, supportive and palliative care and rehabilitation for the benefit of cancer patients and cancer survivors" [7].

The $\mathrm{Pa}^{2} \mathrm{D}$-method was applied to develop a colorectal cancer patient pathway template for CCCNs in Europe. The working group for the development of the template comprised all three roles as specified in section 4.2. The patient pathway template stakeholders built an interdisciplinary and international group of experts in the colorectal cancer domain. The group comprised people from national and international health authorities and societies, national care providers (medical and nursing care) from different $\mathrm{CCCN}$ units, as well as representatives from a European colorectal cancer patient organization. Therewith, the stakeholders also included a subgroup of future patient pathway users. The roles of the patient pathway template designers and the method experts were taken by the authors and colleagues, i.e. information systems experts.

In a systematic review process, existing colorectal cancer pathways and the evidence base (esp. medical guidelines such as $\mathrm{ESMO}^{3}$ clinical practice guidelines) for colorectal cancer care were identified. Additionally, pathways used in the countries and cancer centers of the working group members were collected.

For the main phase of the patient pathway template construction (as described in Figure 2), the scope of the pathway template was defined. It should cover all phases of CCCN care for patients with a suspicion of colorectal cancer and for patients with a histologically confirmed diagnosis. Screening recommendations and activities of primary prevention should not be integrated. The scope definition also included the decision to use BPMN and its domain-specific extensions [23] for pathway template modeling. With this, also quality indicators can be added along the patient pathway. The working progress was organized remotely for most of the time, having physical meetings in-between with the whole or part of the working group.

In the next step, the important steps of the patient pathway template - the process candidates - were identified and the process landscape was defined (see Figure 3). It maps the important processes to the different phases of colorectal cancer care in a CCCN but does not describe relationships between them.

\footnotetext{
${ }^{3}$ ESMO: European Society for Medical Oncology
}

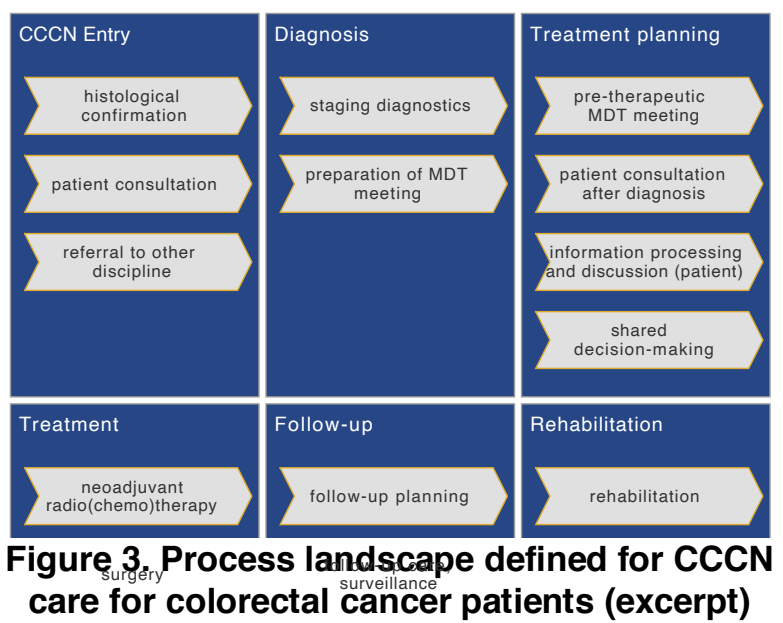

For each process, the input sheets were filled in by the domain experts of the working group and based on the current evidence as identified with the evidence review process. This information was then used to detail the single processes if necessary and to develop a process model of the patient pathway template using a BPMN.io modeling environment adapted to patient pathway specific requirements [23], [28] as presented in Figure 4. Quality indicators were included as blue circles and adaptation notes as comments to the corresponding pathway concepts. The working group regarded comments as sufficient, practical solution for the purpose of adaptation notes. A draft of the template was continuously reviewed by the members of the working group as well as by external domain experts not involved in the development process with background in medical guideline development for the addressed tumor entity until no further revisions were necessary. Then, the template was finally approved. It will be implemented in two pilot CCCNs in Germany and Poland. The implementation and adaptation process will be evaluated and changes to the method might be necessary. After this, the template will function as recommended patient pathway for colorectal cancer patients in European CCCNs.

\subsection{Assessment of the $\mathrm{Pa}^{2} \mathrm{D}$-method}

After the demonstration of the $\mathrm{Pa}^{2} \mathrm{D}$-method's feasibility by using the colorectal cancer use case in section 5.1, we assess its procedure and its results (the patient pathway template) regarding the fulfillment of the initially defined requirements R1 to R7 (see section 3 ). Reflecting on the experiences from the application of the method, we argue the completeness of fulfilling each requirement in Table 4. Additionally, the assessment 


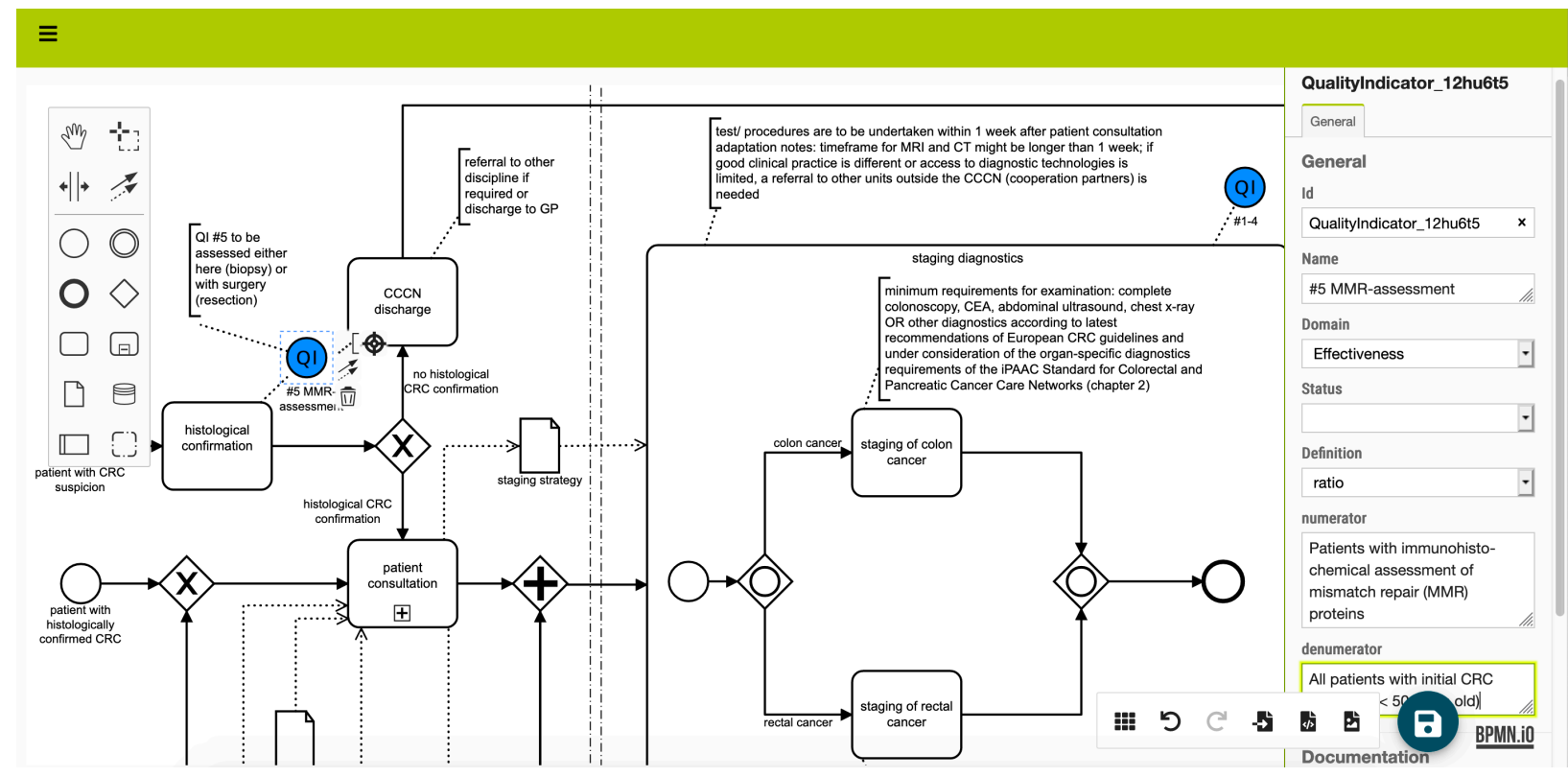

Figure 4. Detail of the colorectal cancer patient pathway template for CCCNs

results of the six completed questionnaires received from the working group are included in Table 4.

In terms of meeting the initially defined requirements, most of them are strongly positive. The results regarding $\mathrm{R} 4$ and $\mathrm{R} 5$ indicate potentials for stronger implementation in the $\mathrm{Pa}^{2} \mathrm{D}$-method. The group processes could be guided in more detail (relating to R4). For example, the consensus procedures could be pre-defined in the method or examples for how to handle different opinions in the working group could be given. In the demonstration case, this was not necessary and the $\mathrm{Pa}^{2} \mathrm{D}$-method in its current version assigns the responsibility for defining the consensus procedure to the users. The results regarding R5 show that the inclusion of the evidence base could be improved. The $\mathrm{Pa}^{2} \mathrm{D}$-method uses the existing evidence base as a major input and complements it with expert knowledge and experiences. In the demonstration case, there were no contradictions identified. However, it is important to keep in mind, that the patient pathway template contents should be developed based on best available evidence. This is not possible for all steps and phases in the pathway, since scientific studies and medical guidelines are rather available for the medical perspective. The specification of the nursing, supportive care or patient perspective is largely based on good practice experiences from the domain experts.

In summary, the procedure of the $\mathrm{Pa}^{2} \mathrm{D}$-method for the development of patient pathway templates was well accepted and rated positively. We asked the members of the working group for their opinion on both what they liked about the procedure for patient pathway template construction and how it could be further improved. The "openness to engage with patient organizations" as well as the "international, inter-disciplinary and multi-level consultations", "compris[ing] multi-sectoral and multinational experience" were highly appreciated. It was highlighted that the $\mathrm{Pa}^{2} \mathrm{D}$-method template development procedure is a "positive interactive process which should assist in creating a clear template for different countries to adapt according to their specific needs but which is at the same time based on evidence". The process was rated "rigorous and well thought-through". The template-based approach was in general well accepted and is expected to have a positive impact especially on creating a uniformly high level of quality care, on reducing the risks and difficulties of patient pathway development for comprehensive care networks, on improving the quality of patient pathways implemented in comprehensive care networks, as well as on improving benchmarking of comprehensive care networks for the same patient populations. Potentials for improvement of the method were stated in terms of increasing the number of meetings (physical or online) to discuss intermediate results. The transparent communication of the planned development procedure in the beginning of the project is said to be of high importance. "[P]iloting [the template] will show bottlenecks" of the method. Then, other possible improvements might become apparent.

\section{Discussion}

We used a user-centered and requirements-driven approach to design the $\mathrm{Pa}^{2} \mathrm{D}$-method to practically support the development and implementation of patient 
Table 4. Requirements-based evaluation of the $\mathrm{Pa}^{2} \mathrm{D}-$ method (1: strongly agree to 5: strongly disagree)

\begin{tabular}{|c|c|c|}
\hline No. & Fulfillment & $\begin{array}{l}\text { Working group } \\
\text { assessment }\end{array}$ \\
\hline R1 & $\begin{array}{l}\text { Separation of template } \\
\text { development and its im- } \\
\text { plementation (template- } \\
\text { based development of a } \\
\text { PP for specific CCN); } \\
\text { template construction } \\
\text { specified as main phase }\end{array}$ & $\begin{array}{llllll}5 & & & & & \\
& & & & & \\
& 1 & & & & \\
& & 0 & 0 & 0 & 0 \\
1 & 2 & 3 & 4 & 5 & \text { NA }\end{array}$ \\
\hline $\mathbf{R 2}$ & $\begin{array}{l}\text { A PP template is } \\
\text { developed for a specific } \\
\text { disease, specified by in- } \\
\text { and exclusion criteria in } \\
\text { the scope definition of } \\
\text { the template construc- } \\
\text { tion phase }\end{array}$ & $\begin{array}{lllllll}4 & & & & & \\
& 2 & & & & \\
& & 0 & 0 & 0 & 0 \\
& & 2 & 3 & 4 & 5 & \text { NA }\end{array}$ \\
\hline $\mathbf{R 3}$ & $\begin{array}{l}\text { Interdisciplinary multi- } \\
\text { stakeholder group is } \\
\text { defined in the role } \\
\text { model; covers different } \\
\text { professions and know- } \\
\text { ledge domains of all PP } \\
\text { stages and CCN units }\end{array}$ & 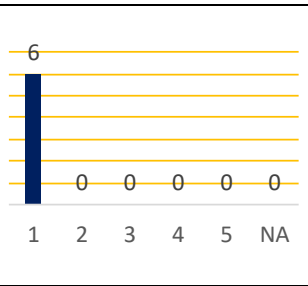 \\
\hline R4 & $\begin{array}{l}\text { The group composition } \\
\text { and consensus finding } \\
\text { process are defined in } \\
\text { the project institution } \\
\text { phase for the PP } \\
\text { template development }\end{array}$ & 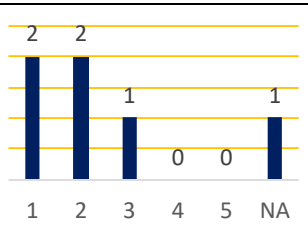 \\
\hline R5 & $\begin{array}{l}\text { Systematic collection of } \\
\text { evidence as separate } \\
\text { phase; PP template con- } \\
\text { struction uses current } \\
\text { evidence base; recom- } \\
\text { mended modeling lan- } \\
\text { guages provide concepts } \\
\text { for representation of } \\
\text { evidence in PP models }\end{array}$ & \begin{tabular}{l|ccccc}
4 & & & & & \\
& 1 & 1 & & & \\
& & & 0 & 0 & 0 \\
& 2 & 3 & 4 & 5 & NA
\end{tabular} \\
\hline R6 & $\begin{array}{l}\text { Obligatory and optional } \\
\text { concepts are defined } \\
\text { with annotations in the } \\
\text { PP template model; } \\
\text { adaptation notes are } \\
\text { described }\end{array}$ & \begin{tabular}{l|lllll}
5 & & & & & \\
& & & & & \\
& 1 & & & & \\
& 1 & 0 & 0 & 0 & 0 \\
1 & 2 & 3 & 4 & 5 & NA \\
\end{tabular} \\
\hline R7 & $\begin{array}{l}\text { Patient representatives } \\
\text { are explicitly included } \\
\text { as PP template } \\
\text { stakeholders; a patient } \\
\text { view with specific tasks } \\
\text { is included in the PP } \\
\text { template (BPMN lane) }\end{array}$ & 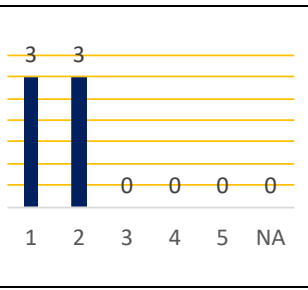 \\
\hline
\end{tabular}

pathways in comprehensive care networks. The method pathways in comprehensive care networks. The method provides the description of roles to be involved and describes a template-based patient pathway development procedure. The method was assessed by demonstrating its applicability with the use case of oncology care. A patient pathway template for colorectal cancer was developed by in international, interdisciplinary multi-stakeholder working group, who positively assessed the method based on their experiences with the development process.

Critically reflecting on the limitations of our approach, the requirements used for the method development might not be complete. Further requirements might lead to changes in the $\mathrm{Pa}^{2} \mathrm{D}$-method design. However, the requirements are supported by the findings of a former literature review on the topic of methodological support for patient pathway development in [9]. Also, the $\mathrm{Pa}^{2} \mathrm{D}$-method fits into the existing literature on methodological support for the development and implementation of pathways in healthcare. It includes, combines and especially details the necessary steps described in other literature (e.g. referring to [8], [10]-[13]). Reflecting on the application and evaluation of the $\mathrm{Pa}^{2} \mathrm{D}$-method, it needs to be applied for more cases than the one we demonstrated in section 5. It is currently also applied for the development of a pancreatic cancer patient pathway template but should also be used and tested outside of the oncology care domain in the future. Also, the implementation and adaptation of the template in specific comprehensive care networks will be necessary to demonstrate and evaluate the method in a more comprehensive manner. This will be conducted with both the colorectal and pancreatic patient pathway template in pilot CCCNs in Germany and Poland. A long-term evaluation of implemented patient pathways is desirable as well. Currently, the evaluation of pathways and their impact is rather on outcomes such as time, resources and costs [29]. With the patient pathway approach, rather patient- and network-centered evaluation approaches are needed - including outcome measures concerning patient and disease progression (e.g. disease management, quality of life, patient empowerment), coordination, or communication, which characterize integrated care [30].

\section{Conclusion}

With the $\mathrm{Pa}^{2} \mathrm{D}$-method, we provide practical guidance for the development and implementation of patient pathways in comprehensive care networks. Designing the method, a user-driven and requirementsbased procedure was followed. The template-based approach for patient pathway development aims to support uniformly high quality for comprehensive care 
networks and to simplify and standardize the development process. The $\mathrm{Pa}^{2} \mathrm{D}$-method was already tested in the field of oncology care by developing a patient pathway template for colorectal cancer care in CCCNs. A template for pancreatic cancer is under development. After implementing the templates in two European pilot CCCNs and thus, further testing and potentially improving the method itself, the $\mathrm{Pa}^{2} \mathrm{D}$ method will become part of the certification program in European cancer care. This underlines its high innovation and dissemination potentials. The work pushes standardized patient pathway development and the large-scale implementation in comprehensive care networks - thus, supporting the implementation of integrated care. The $\mathrm{Pa}^{2} \mathrm{D}$-method can increase the usage of patient pathways in care practice and serve as basis for their evaluation.

\section{Acknowledgment}

The work for this article was funded by the European Union's Health Programme (2014-2020). We thank the members of IPAAC WP10 for their fruitful feedback.

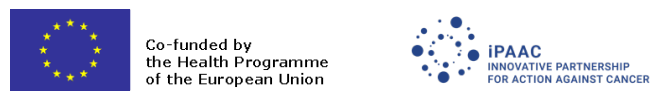

\section{References}

[1] European Pathway Association, "Care Pathways," European Pathway Association. http://e-p-a.org/carepathways/ (accessed June 15, 2020).

[2] P. Richter and H. Schlieter, "Understanding Patient Pathways in the Context of Integrated Health Care Services Implications from a Scoping Review," in Proc 14th Int Conf on Wirtschaftsinformatik, 2019, pp. 997-1011.

[3] L. De Bleser et al. "Defining pathways.," J Nurs Manag 14(7), pp. 553-563, 2006.

[4] P. P. Valentijn et al., "Understanding integrated care: a comprehensive conceptual framework based on the integrative functions of primary care," Int J Integr Care 13, p. e010, 2013. [5] S. V. Lerum and J. C. Frich, "Normative assumptions in integrated care: A conceptual discussion," Int J Healthc Manag 5(1), pp. 32-39, 2012.

[6] R. Busse, M. et al., Tackling chronic disease in Europe. Strategies, interventions and challenges. Kopenhagen, 2010.

[7] T. Albreht, R. Kiasuwa, and M. Van der Bulcke, Eds., EUROPEAN guide on quality improvement in comprehensive cancer control. Ljubljana: National Institute of Public Health; Brussels: Scientific Institute of Public Health, 2017.

[8] S. McLachlan et al., "Clinical Caremap Development: How can caremaps standardise care when they are not standardised?," in Proceedings of the 12th International Joint Conference on Biomedical Engineering Systems and Technologies (BIOSTEC 2019), pp. 123-134.

[9] P. Richter and H. Schlieter, "Paving the Way for Patient Pathways: Synthesizing a User-Centered Method Design with Results from a Systematic Literature Review," in Proc 15th Int Conf on Wirtschaftsinformatik, 2020.
[10] M. Gordon, "Steps to pathway development," J Burn Care Rehabil 16(2) Pt 2, pp. 197-202, 1995.

[11] E. J. Flores et al., "Using a 10-step framework to support the implementation of an evidence-based clinical pathways programme," BMJ Qual Saf, p. bmjqs-2018-008454, 2018.

[12] S. Ferranteet al., "A design methodology for medical processes," Appl Clin Inform 7(1), pp. 191-210, 2016.

[13] K. Vanhaecht et al., "The 7-phase method to design, implement and evaluate care pathways," Int J Pers Centered Med 2(3), pp. 341-351, 2012.

[14] L. Kinsman et al., "What is a clinical pathway? Development of a definition to inform the debate," BMC Med. 8, pp. 31-33, 2010.

[15] P. Fettke and P. Loos, Reference Modeling for Business Systems Analysis. Hershey, PA: IGI Publishing, 2006.

[16] A. R. Hevner et al., "Design science in information systems research," Manag Inf Syst Q 28(1), pp. 75-106, 2004. [17] S. W. Ambler, "Introduction to User Stories. Initial User Stories (Formal)," Agile Modeling. http://www.agilemodeling.com/artifacts/userStory.htm\#Initia 1Formal (accessed Feb. 08, 2019).

[18] P. Mayring, "Qualitative Content Analysis," Forum Qual Soc Res 2(1), pp. 1-10, 2000.

[19] S. Brinkkemper, "Method engineering: engineering of information systems development methods and tools," Inf Softw Technol 38(4), pp. 275-280, 1996.

[20] E. Mumford, "The story of socio-technical design: reflections on its successes, failures and potential," Inf Syst J., 16(4), pp. 317-342, 2006.

[21] C. Wicke et al., "Design and use of patient pathways in general surgery," Chirurg 75(9), pp. 907-915, 2004.

[22] P. Mincarone et al., "Standardized languages and notations for graphical modelling of patient care processes: a systematic review.," Int J Qual Health Care J Int Soc Qual Health Care 30(3), pp. 169-177, 2018.

[23] R. Braun et al., "BPMN4CP Revised - Extending BPMN for Multiperspective Modeling of Clinical Pathways," in Proc 49th Hawaii International Conference on System Sciences (HICSS), 2016, pp. 3249-3258.

[24] K. Vanhaecht et al., "The 3-blackboard method as consensus-development exercise for building care pathways," Int J Care Pathw 15(2), pp. 49-52, 2011.

[25] OCEBM Levels of Evidence Working Group, "The Oxford 2011 Levels of Evidence," CEBM - Oxford Centre for Evidence-Based Medicine, 2011. https://www.cebm.net/ index.aspx?o=5653 (accessed Jul 07, 2020).

[26] M. I. Fitch, "Supportive care framework," Can Oncol Nurs J Rev Can Nurs Oncol 18(1), pp. 6-24, 2008.

[27] H. Schlieter et al., "Governance in Hospitals - The Case of Business Process Alignment," in Proc Americas Conference on Information Systems (AMCIS) 2012.

[28] P. Richter and H. Schlieter, "Process-Based Quality Management in Care: Adding a Quality Perspective to Pathway Modelling," in On the Move to Meaningful Internet Systems: OTM 2019 Conferences, Cham, 2019, pp. 385-403, [29] E. Aspland et al., "Clinical pathway modelling: a literature review," Health Syst, pp. 1-23, 2019.

[30] M. Minkman, "The Development Model for Integrated Care: a validated tool for evaluation and development," $\mathrm{J}$ Integr Care 24(1), pp. 38-52, 2016. 